A N N A L E S

UNIVERSITATIS M A R A E C URIE-SKŁODOW S A

LUBLIN - POLONIA

VOL. LXXII

SECTIO F

2017

Pädagogische Universität in Krakau

ZDZISŁAW NOGA

nogaz@up.krakow.pl

\title{
Die Selbstverwaltung der Stadt Krakau in vorindustrieller Zeit
}

Samorząd miasta Krakowa w czasach przedprzemysłowych

\section{ZUSAMMENFASSUNG}

Die Stadt Krakau funktionierte seit ihrer Lokation (1257) bis zur Verfassung vom 3. Mai 1791 nach Magdeburger Recht, aber auch die örtlichen Zünfte besaßen eine Stadtgemeindeordnung. In der Anfangszeit der Lokationsstadt spielten Erbvögte und die sog. Gerichtsbank die Hauptrolle. Nach der Konfiszierung des Vogtamtes durch Herzog Władysław Łokietek (Ellenlang) im Jahre 1312 infolge einer Rebellion des Vogtes Albert kam es dann zur Degradierung dieses Organs. Seitdem übten die Vögte nur noch Gerichts- und Polizeifunktionen aus und waren vom Stadtrat abhängig.

Dieses Organ war kurz nach der Lokation der Stadt entstanden. Anfangs vom Vogt ernannt und danach durch Kooptierung ergänzt, war es ein echter Repräsentant der Stadtbewohner. Eine Konsequenz der Rebellion des Vogtes Albert war der Verlust der vollen Autonomie der Stadtgemeinde, und von nun ab ernannte den Rat alljährlich der Herrscher oder sein Beamter, seit dem 15. Jahrhundert der Krakauer Wojewode, der acht amtierende Ratsherren auswählte, während die vorher amtierenden Ratsherren, die in diesem Jahr nicht ausgewählt wurden, einen 16 Personen starken Altenrat bildeten. Das Amt war auf Lebenszeit. Erst Ende des 17. Jahrhunderts erlangte der Rat das Recht, neue Ratsherren zu wählen. Dieses Organ erlangte eine privilegierte Position in der Stadt und konzentrierte in seiner Hand alle wichtigsten Kompetenzen, darunter die Nominierung der Schöffen und der Berufsbeamten mit dem Schreiber und dem Syndikus an der Spitze, sowie die Vertretung der Stadt in den Kontakten nach außen. Von einer zahlenmäßig kleinen Gruppe von Familien besetzt, wurde es zu einer oligarchischen Institution, die sich hauptsächlich um die Interessen der eigenen Gruppe kümmerte, zum Nachteil der meisten Bürger, die erst nach Konflikten im 16. Jahrhundert das Recht auf Kontrolle der öffentlichen Finanzen durch eine als Quadragintavirat bezeichnete eigene Vertretung erlangten. Schließlich bildete sich in de zweiten Hälfte des 17. Jahrhunderts eine breite Vertretung des einfachen Volkes - der communitas - heraus, die die Funktionen des Quadragintavirats übernahm. Diese Institutionen wachten über die Autonomie der Stadtgemeinde und gestalteten über Jahrhunderte hinweg die bürgerlichen Haltungen der Krakauer.

Schlüsselwörter: Krakau; Stadtordnung; Magdeburger Recht; Stadtrat; Quadragintavirat 
Die Autonomie der Gemeinde war einer der Fundamente der Städte in Polen in vorindustrieller Zeit. Im Prozess der Urbanisierung Kleinpolens, die in der Mitte des 13. Jhs. begann, bekamen die Städte in den Privilegien Stadtrecht, und das Magdeburger Modell überwog, obwohl sich die Stadtordnung der einzelnen Städte in Details unterschied ${ }^{1}$.

Die Anfänge der autonomen Krakauer Stadtgemeinde (communitas) mit ihrer eigenen Selbstverwaltung kann man seit der Lokation der Stadt in 1257 nach Magdeburger Recht verbinden, obwohl Krakau als Stadt schon Jahrzehnte früher funktionierte 2 . In den Anfängen der autonomen Stadt war der Vogt der wichtigste Beamte. Diese Funktion übernahmen als erste die aus dem Lokationsprivileg bekannten Organisatoren der Stadt, Neuankömmlinge aus Schlesien: Gedko Stilvoyt, Dethmar Wolk (beide wahrscheinlich aus Breslau), Jakob - einst Richter in Neiße (Schlesien). Auf diese Weise wurden die Gründer der Stadt für ihre eigene Arbeit und ihren Kapitalaufwand vergütet. Nach einiger Zeit verkauften sie die Vogtei und im 13. Jh. gehörte sie den Erben der obengenannten Stadtgründer. Es wird auch vermutet, dass neben diesen auch sog. Gerichtsvogte funktionierten, die im Stadtgericht tätig waren ${ }^{3}$.

Die Krakauer Vogtei gehörte seit Ende des 13. Jhs. Albert, der 1311 die Revolte gegen den polnischen Fürsten Władysław Łokietek (Ellenlang) begann ${ }^{4}$. Die Niederschlagung der Revolte hatte negativen Einfluss auf die Bedeutung dieser Institution. Eine der Folgten war die Ende der dominierenden Stelle der Vogtei in der Stadt. Der Fürst Władysław Łokietek beschlagnahmte die Krakauer Vogtei in Rahmen der Repressionen, ohne dass sie in erblichen Besitz überging, sondern ausschließlich in Pacht gegeben wurde. Seit dieser Zeit verloren die Vögte an wirtschaftlicher Bedeutung und ihre Funktion beschränkte sich auf Verwaltungs- und gerichtliche Pflichten: sie leiteten die Bank und übten auch polizeiliche Pflichten aus. Dies ergab sich aus dem Wesen des Magdeburger Rechts, im Sinne dessen die Vogtei ein unentbehrliches Element

1 J. Ptaśnik, Miasta i mieszczaństwo w dawnej Polsce [Die Städte und Stadtbürger in der alten Polen], Kraków 1949, S. 33-35; M. Bogucka, H. Samsonowicz, Dzieje miast i mieszczaństwa $w$ Polsce przedrozbiorowej [Die Geschichte der Städte und Stadtbürger in Polen vor den Teilungen], Wrocław 1986, S. 49.

2 J. Wyrozumski, Lokacja czy lokacje Krakowa na prawie niemieckim? [Die Lokation oder die Lokationen Krakaus nach dem deutschen Recht?], [in:] Kraków. Nowe studia nad rozwojem miasta [Krakau. Neue Studien über die Stadtentwicklung], red. J. Wyrozumski, Kraków 2007, S. $125-143$.

3 M. Niwiński, Wójtostwo krakowskie w wiekach średnich [Das Krakauer Vogtamt im Mittelalter], Kraków 1938, s. 46-98; J. Rajman, Kraków. Zespót osadniczy, proces lokacji, mieszczanie do roku 1333 [Krakau. Siedlungskomplex, Lokationsprozess, Stadtbürger bis 1333], Kraków 2004, S. 244.

4 J. Wyrozumski, Dzieje Krakowa [Geschichte der Stadt Krakau], t. 1: Kraków do schyłku wieków średnich [Krakau bis zum Ende des Mittelalters], Kraków 1992, S. 199-211. 
der Gesellschaftsordnung der Stadt war ${ }^{5}$. Letztendlich nahm, wie in manchen anderen polnischen Städten auch, der Stadtrat die Vogtei zuerst in Pacht im Jahre 1332 und kaufte sie dann im Jahre 1475 für 1000 Mark von Peter Lang ab. Die formelle „Inkorporation“ in die Stadtgemeinde fand aber erst im Jahre 1616 statt $^{6}$. Die Übertragung des Vogteieigentumsrechts auf die Stadtgemeinde bedeutete einen Rückgang des Prestiges und der faktischen Bedeutung der Vögte, die seit dieser Zeit vom Rat ernannt wurden und damit keine Konkurrenten mehr auf dem Gebiet der Stadt waren. Die Vogtei wurde eine völlig dem Ratskollegium untergeordnete Institution und die Vögte durften sich nicht im laufenden politischen Kampf engagieren.

Ohne die Rolle der Vögte im Prozess der Gründung Krakaus zu schmälern, muss jedoch betont werden, dass sie nicht die Interessen der Stadteinwohner vertraten. Sie waren ja keine gemeinen Bürger, und schon zu Beginn Tätigkeit waren sie eigentlich Vermittler zwischen dem Eigentümer der Stadt Krakau und ihren Einwohnern. Sie wurden für ihre Tätigkeit bei der Gründung der Stadt sehr gut vergütet und kümmerten sich vor allem um ihre eigenen Interessen. Eine die Interessen der Einwohner tatsächlich vertretende Institution war erst der Stadtrat, dem, anfangs vom Vogt und der Gerichtsbank beherrscht, es noch im 13. Jahrhundert gelang, die wichtigste Rolle unter den Systeminstitutionen Krakaus zu spielen.

Die Anfänge des Stadtrates in Krakau sind aufgrund mangelnder Quellen immer noch nicht völlig klar. Die Diskussion darüber hat letztens Marcin Starzyński ausführlich besprochen ${ }^{7}$. Nach heutigem Wissen entstand er wahrscheinlich bald nach der Lokation der Stadt (spätestens bis 1264). Das älteste Ratskollegium wurde zuerst vom Vogt ernannt und dann jedes Jahr vom zurücktretenden Rat gewählt.

Wie schon gesagt wurde, hatte die Gemeinde der Stadt Krakau ihre Autonomie nach der Revolte des Vogtes Albert teilweise verloren. Obwohl der Rat als Institution an der Revolte nicht teilgenommen hatte, wechselte Fürst Wladyslaw Ellenlang diese Institution aus und nominierte am 14. Juni 13127 neue Bürger zum Rat ${ }^{8}$. Diese Nominierung eröffnete eine neue Epoche in der Stadt. Der Rat verlor das Privileg einer Kooptierung neuer Ratsherren. Erst haben die Könige den Rat nominiert, dann verschiedene Staatsbeamten im Namen der Monarchen, und seit Ende des 14. Jahrhunderts wurden die Ratsherren vom Krakauer Wojewoden aus dem Kreis der ihm vom aktuellen Rat vorgestellten Kandidaten „gewählt“,

5 W. Bukowski, Z. Noga, Ustrój miasta Krakowa w XIII-XVIII wieku [Die Grundordnung der Stadt Krakau in 13.-18. Jh.], [in:] Kraków europejskie miasto prawa magdeburskiego 12571791 [Krakau, eine europäische Stadt Magdeburger Rechts 1257-1791], Kraków 2007, S. 50-52.

6 Z. Noga, Urzędnicy miejscy Krakowa [Die Beamten der Stadt Krakau], cz. 2: 1500-1794, Kraków 2008, S. XXXI.

7 M. Starzyński, Krakowska rada miejska w średniowieczu [Der Krakauer Stadtrat im Mittelalter], Kraków 2010, S. 29.

8 Ibidem, S. 61-64. 
d.h. ernannt. Erst über drei Jahrhunderte später bekam die Stadtgemeinde nach vielen Bemühungen in den Jahren 1677-1679 dieses Privileg zurück und der bisherige Rat erhielt das Recht, den amtierenden Rat zu ernennen. Von dieser Zeit an bis zum Untergang der Ersten Republik Polen wurden die Beamten völlig selbständig durch die Stadt gewählt, und die Menschen, die das Erreichen des königlichen Privilegs gefördert hatten, wurden reichlich von der Stadtkasse belohnt ${ }^{9}$.

Die Zahl der Ratsherren war am Anfang der Stadtgemeinde nicht beständig. Obwohl die Quelleninformationen über die ältesten Ratsherren manche Lücken haben, kann man annehmen, dass diese Institution zuerst 6 Ratsherren bildeten, aber seit Anfang des 15. Jahrhunderts hatten dann schon 8 Bürger einen festen Sitz im Rat ${ }^{10}$. Gleichzeitig gestaltete sich infolge der Verständigung zwischen dem aktuell amtierenden Rat und ehemaligen Ratsherren die Gewohnheit, ehemalige Ratsherren in die Verwaltung der Stadt miteinzubeziehen. Auf diese Weise entstand der ,alte“ Rat und seit dieser Zeit setzte sich der Krakauer Stadtrat aus 24 Ratsherren zusammen, indem er in einen amtierenden (8 Personen) und einen ,,alten“(16 Personen) Rat geteilt wurde. Der amtierende Rat wurde jedes Jahr durch den Krakauer Wojewoden unter den Ratsherren, die schon einen Sitz im Rat hatten, ausgewählt. „Neue“ Ratsherren konnten nur die Stelle Verstorbener oder Entlassener einnehmen. Es galt dann das willkürlich vom Rat im ersten Viertel des 15. Jahrhunderts herkömmlicherweise in Kraft getretene Prinzip, dass dieses Amt auf Lebenszeit verbindlich war. Diese consules novi begannen mit dem Beisitz im amtierenden Rat. Jeder amtierende Ratsherr übte die Funktion des Bürgermeisters sechs Wochen lang aus. Für die Reihenfolge war die Zeitdauer der Ausübung des Amtes entscheidend. Ein neu ernannter Ratsherr trat das Amt erst am Ende seiner Wahlperiode an, ,damit er es sich ansehen und von Älteren lernen kann, wie er seine Pflichten ausüben soll"“11.

Seit dem späten Mittelalter war es Sitte, dass der Beförderung zum Rat ein Praktikum in der Gerichtsbank vorausgehen soll. Laut Dekret des Königs Sigismunds I. vom 12. März 1507 wurde die jetzige Sitte, zum Rat nur Stadtschöffen zu kooptieren, zur Rechtsvorschrift. Von der Pflicht eines Praktikums in der Bank waren Personen ausgeschlossen, die eine entsprechende Erfahrung oder Ausbildung hatten, zum Beispiel Kandidaten mit dem Titel „Doktor“ wie auch Stadtschreiber und Sindizi. Daher hatten nie Ärzte oder Juristen mit einem akademischen Grad einen Beisitz im Schöffengericht. Sie begannen sofort ihre Laufbahn als Beamte im Stadtrat ${ }^{12}$.

9 J. Bieniarzówna, Mieszczaństwo krakowskie XVII w. Z badań nad struktura społeczna miasta [Die Krakauer Bürgerschaft des 17. Jhs. Forschungen zur sozialen Struktur der Stadt], Kraków 1968, S. 16-17.

${ }_{10}$ W. Bukowski, Z. Noga, op. cit., S. 49-68.

11 J. Ptaśnik, Kilka słów o dawnej radzie [Ein paar Worte über den ehemaligen Rat], [in:] Obrazki z przeszłości Krakowa [Bilder aus der Vergangenheit Krakaus], Kraków 1902, S. 45.

12 Z. Noga, Krakowska rada miejska w XVI wieku. Studium o elicie władzy [Der Krakauer Rat im 16. Jh. Studium über die Herschaftselite], Kraków 2003, S. 33-34. 
Ein herkömmlicher Termin der Ernennung des Rates, d.h. „der Bestimmung der Ratsherren“, war in Krakau der Folgesonntag nach dem Dreikönigstag. Dieser Termin galt im Prinzip bis zum Ende des 18. Jahrhunderts. Allerdings konnte er aus unterschiedlichen Gründen nicht immer eingehalten werden. Verzögerungen ergaben sich manchmal aus der Abwesenheit des Wojewoden in der Stadt oder aus Änderungen auf diesem Posten, Kriegen und Naturkatastrophen, die das Leben der Stadt verwirrten, und letzten Endes aus der Notwendigkeit, den Termin dieser Feier staatlichen und höfischen Feierlichkeiten anzupassen, was im Jahre 1525 der Fall war, als der Termin der Wahl des Rates auf den 6. April verschoben wurde. Sie fand vier Tage vor dem sog. Preußischen Lehnseid von Albrecht Hohenzollern statt ${ }^{13}$.

Solange der Grundsatz galt, den Rat vom Wojewoden zu wählen, fand die Ernennung der Ratsmitglieder einmal im Jahr statt. Eine Ausnahme bildete das Jahr 1604, als zwei Ratsherren dieses Amt ablehnten und den Eid nicht ablegten. Der Wojewode ernannte einige Wochen später zwei andere Bürger, die individuell vereidigt wurden: Jan Cyrus am 20. Januar und Stanisław Rapp am 26. Februar. Seitdem der Rat das exklusive Recht auf die Wahl des amtierenden Rates hatte, galt zwar das Prinzip der alljährlichen Ernennung. Aber es wurden auch Kooptierungen zum Rat zu anderen Terminen durchgeführt, vor allem wenn Seuchen und ansteckende Krankheiten viele Opfer im Rat gefordert haben. Ein Grund für diese außerordentlichen Ernennungen war die Sorge um das richtige Funktionieren des Amtes. Die Ernennung eines Nachfolgers - im Falle des Todes eines Ratsherrn - erfolgte gewöhnlich schnell, innerhalb von ein paar Tagen. Wenn es aber Streitigkeiten zwischen miteinander konkurrierenden Gruppen im Rat gab, dann zogen sich die Ernennungen ins Unendliche ${ }^{14}$.

Die alljährliche Ernennung zum Rat war in Krakau ein großer, besonderer Festtag, der jahrhundertelang den Rhythmus des öffentlichen Lebens der Gesellschaft bestimmte. Der Termin der Ernennung zum Rat - der Folgesonntag nach dem Dreikönigstag - war kein Zufall und er nahm auf biblische Symbole Bezug. Die Ratsherren in Krakau verglichen sich - ähnlich wie in vielen anderen europäischen Städten - mit den frommen, biblischen Weisen aus dem Morgenland. Das mit der Ernennung verbundene, ausgebaute und kostenaufwändige Zeremoniell hatte seine eigene Symbolik und diente der Legitimierung der Behörde. Es war auch ein „Medienereignis“. Der Rat demonstrierte den versammelten Bürgern gegenüber seine eigene, politische Position und das Prestige des Amtes, und die neu gewählten Mitglieder hatten die Gelegenheit, öffentlich vorgestellt zu werden. Die Zeremonie der Wahl begann vormittags. Die Krakauer wurden vom Trompeter im Turm der Marienkirche vorgeladen, der die Trompete blies, wenn der Wojewode oder sein Vertreter in der Umgebung von Hofleuten feierlich aus

${ }_{13}^{13}$ M. Starzyński, op. cit., S. 28.

14 Z. Noga, Urzędnicy miejscy..., S. XIV-XVI. 
dem Wawel in der Stadt ankam. Alle gingen zuerst in die Marienkirche. Nach der Messe begab sich der Wojewode ins Rathaus. Dort verlas ein Stadtschreiber das Dokument des Wojewoden (und seit 1679 des Rates) mit 8 Namen der in diesem Jahr amtierenden Ratsherren vor. Die Ratsherren begannen dann im Rathaus ein Gastmahl mit eingeladenen Gästen, unter denen es auch am Hof verkehrende Würdenträger gab. Immer bestand die Gelegenheit, die finanzielle Macht der Stadt darzustellen. Die prunkvollen und kostenaufwändigen Schmäuse anlässlich der Wahlen wurden besonders sorgfältig vorbereitet. Die Gastmähler im Rathaus wurden im Interesse der Stadt organisiert. Sie dienten dem Anknüpfen und Fortdauern der Kontakte mit den wichtigsten Staatsbeamten. Der Rat vertrat die Gemeinde in den Kontakten mit den wichtigsten Personen und Institutionen des Staates und brauchte solche Kontakte, um die Interessen der Gemeinde zu verteidigen. Noch im 15. und 16. Jahrhundert hatte die Stadt indirekte Kontakte mit den Monarchen und mit dem königlichen Hof, dank so einflussreichen Ratsherren wie z. B. Jan Boner oder Jost Ludwig Dietz. Seit Ende des 16. Jhs., als Krakau die Residenzfunktionen verlor, musste der Stadtrat Vermittler am königlichem Hof suchen und sie für Entscheidungen oder Informationen bezahlen, die für die Stadt wichtig waren ${ }^{15}$.

Bei inneren Angelegenheiten konnte der Rat seine starke Position jedoch halten. In seinem Kompetenzbereich lag die alljährliche Nominierung der anfänglich 7-, ab 1392 dann 11-köpfigen Gerichtsbank (Schöffenbank), des zweiten Organs der Selbstverwaltung, das in Krakau seit Gründung der Stadt bestand und in vollem Umfang vom Rat abhängig war. Den Schöffen stand allein die Wahl eines Seniors zu, die gerichtlichen Kompetenzen jedoch wurden vom Rat übernommen. Die Ratsherren hatten auch ihre Stadtschreiber, Sindizi und eine damals noch nicht so gut entwickelte Schicht an ,mittleren“ Stadtbeamten ${ }^{16}$.

Innerhalb des Rates übten die Ratsherren verschiedene Funktionen aus, von deren die wichtigsten für die Finanzen der Stadt verantwortlich waren. Seit Anfang des 16. Jahrhunderts wurde es Sitte, dass diese Pflicht zwei Lohnherren übernahmen, die von den Ratsherren so gewählt wurden, dass der erste aus dem ,alten“ Rat, der zweite aus dem amtierenden Rat kam. Seit 1521 wurden sie jedes Jahr gewählt. Die Wahl wurde kurz nach der Wahl des Rates für das gegebene Jahr, meistens etwa am Tage der heiligen Agnieszka (am 21. Januar), durchgeführt. Das Amt eines Lohners genoss im 17. Jahrhundert keine Popularität, weil es sehr zeitraubend war. Aus diesem Grunde ließ 1639 der Stadtrat Stadtschöffen und Vertreter des gemeinen Volkes (der sog. dritten Ordnung) zu den Stadtfinanzen zu, indem die Vergrößerung der Anzahl von Lohnherren auf vier und eine Teilung beschlossen wurde. Zwei Ratsherren - Lohner (primi ordinis) beschäftigten sich

\footnotetext{
${ }^{15}$ Idem, Krakowska rada miejska..., S. 25-30.

16 W. Bukowski, Z. Noga, op. cit., S. 49-68.
} 
bis jetzt mit den Ausgaben für Beamte und den Magistratsdienst, verwalteten Geschenke, Unterstützungsgelder und Stadtmieten, versorgten finanziell die Krakauer Abgeordneten des Sejm und der Landesregierungen sowie die Würdenträger, zwei andere Lohner (secundi ordinis) dagegen - einer wurde unter den Schöffen, der andere unter dem gemeinen Volk ausgewählt - übten die Aufsicht über alltägliche wirtschaftliche Angelegenheiten der Stadt aus. Diese Situation dauerte nicht lange. Im Jahre 1653 kehrte man zur alten Ordnung zurück, indem die Anzahl von Lohnherren auf zwei begrenzt wurde. Am Anfang des 17. Jahrhunderts wurde dagegen das Amt des Lohners wieder reformiert, indem ein Lohner (Ratsherr) und zwei Lohner von niedrigerem Rang unter dem Volk gewählt wurden. Außer den Lohnherren gehörten zu den renommierten Ratsherren auch 2 vitrici der Marienkirche, die diese Funktion auf Lebenszeit bekamen ${ }^{17}$.

Der Rat beaufsichtigte die Verteidigung der Stadtmauern und hatte die Pflicht, über die Sicherheit in der Stadt zu wachen, was keine einfache Aufgabe war, wenn man die Mengen adliger Gäste berücksichtigt, die in die Hauptstadt und auf den Königshof zogen. Viele Probleme verursachten auch die Studenten der 1364 gegründeten Universität, die dem Gericht des Rektors unterstanden, und die Stadtverwaltung hatte auch keinen Einfluss auf ihre Tätigkeit, was am besten in der Zeit der Reformation zu sehen war ${ }^{18}$. Die öffentliche Ordnung wurde jedoch nicht nur von Adligen und Studenten verletzt. Krakau war voll von „freien“ Menschen, ohne einen festen Beruf und ohne einen Wohnort, die in der Residenzstadt der polnischen Könige nach einem leichteren Leben suchten. Die Gerichtsbarkeit des Rates umfasste weder Menschen, die keine Adligen waren, noch die innerhalb der Stadtmauer und im Umkreis von zwei Meilen außerhalb der Mauer gelegenen kirchlichen und adligen Immobilien (jurydyka), Kirchen und Klöster und die Universität. Der Rat war dagegen für die Verletzung der öffentlichen Ordnung verantwortlich, wodurch er häufig in Verlegenheit geriet. Trotz der großen Verantwortung und sogar eines gewissen Risikos genoss der Sitz im Rat ein Ansehen und brachte Vermögensvorteile mit sich. Daher gab es in diesem Kreis Vertreter der bedeutendsten Familien des Krakauer Patriziats ${ }^{19}$.

17 Z. Noga, Rola samorzadu w rozwoju miasta $w$ XIII-XVIII wieku [Die Rolle der Selbsverwaltung in der Entwicklung der Stadt im 13.-18. Jh.], [in:] Kraków. Nowe studia nad rozwojem..., S. 464-465.

18 J. Bieniarzówna, J.M. Malecki, Dzieje Krakowa [Geschichte der Stadt Krakau], t. 2: XVIXVIII w., Kraków 1984, S. 124-144.

19 Über die Ratsherrenfamilien und die Mobilität in der politischen Führungsschicht Krakaus existiert eine umfangreiche Literatur, z. B.: J. Ptaśnik, Studia nad patrycjatem krakowskim wieków średnich [Studien über das Krakauer Patriziat des Mittelalters], „Rocznik Krakowski” 1912, t. 15, S. 55-61; W. Bukowski, Salomonowie herbu Łabędź. Ze studiów nad patrycjatem krakowskim wieków średnich [Die Familie Salomon mit Wappen Łabędź. Studien zum Krakauer Patriziat im Mittelalter], [in:] Cracovia. Polonia. Europa. Studia z dziejów średniowiecza ofiarowane Jerzemu Wyrozumskiemu $w$ sześćdziesiąta piąta rocznice urodzin i czterdziestolecie pracy naukowej, 
Der überwiegende Teil der Bürger, unter denen die Handwerker eine bedeutende Gruppe darstellten, hatte auf das politische Leben keinerlei Einfluss. Versuche König Kasimirs des Großen, den Zünften eine Vertretung in der städtischen Verwaltung zu verschaffen, indem er anordnete, die Hälfte der Räte müsse aus Handwerken, die andere aus Kaufleuten bestehen, schlugen fehl. Der Kaufmannsstand konnte seine dominierende Rolle behaupten ${ }^{20}$. Im Laufe der Jahre kam es zu einer Oligarchisierung der politischen Führungsschicht.

Mit der Zeit veränderte der Rat sein Antlitz und wandelte sich von einer echten Vertretung der Bürger in eine Art oligarchischer Institution, die trotz Ermangelung vollständiger Autonomie unlautere Methoden verwandte oder tatsächlichen Einfluss auf die Nominierung von Ratsherren nahm, indem diese Posten Mitgliedern aus der eigenen Familie zugänglich gemacht wurden. Dieser ,oligarchisierte“ Rat kümmerte sich in erster Linie um die Interessen der Ratsmitglieder, indem man untereinander das Pachtrecht für Kramläden, Mietpreise und sonstige Bestandteile städtischen Eigentums aufteilte. Öffentliche Gelder wurden ohne jedwede Kontrolle ausgegeben, was letztlich im 16. Jh. Konflikte in der Stadt heraufbeschwor. Das gemeine Volk wandte sich in dieser Sache 1521 an König Sigismund I., der den Rat daraufhin verpflichtete, die Ein- und Ausgaben von einer Bürgervertretung abrechnen zu lassen, die sich aus 12 Vertretern des Kaufmannsstandes und 20 Zunftmeistern zusammensetzte. Im Jahr 1524 ließ der König diesem Kreis noch eine Gruppe von 11 Schöffen hinzufügen. Nach und nach begann man, diese Institution als Quadragintavirat zu bezeichnen und anfänglich war sie eine tatsächliche Vertretung der Bürger dieser Stadt ${ }^{21}$. Aus einem später verfassten Dokument (1578) geht hervor, dass die Zunftmeister die Vertreter der Kaufleute wählten, die Kaufleute wiederum die Repräsentanten des Handwerksstandes ${ }^{22}$.

$\mathrm{Ab}$ Beginn des 17. Jhs. verlor das Quadragintavirat jedoch an Bedeutung, nachdem es bei Streitigkeiten mit dem Rat zum wiederholten Male Rückschläge erlitten hatte. Nach einem Konflikt in den Jahren 1623-1626 wurden die aktivsten Vertreter des gemeinen Volks ihrer bisherigen Funktion enthoben und verloren so

[Festschrift für Jerzy Wyrozumski], Kraków 1995, S. 113-145; Z. Noga, Krakowska rada miejska...; J. Bieniarzówna, Mieszczaństwo krakowskie..., S. 123-136.

${ }^{20}$ W. Bukowski, Z. Noga, op. cit., S. 58.

${ }^{21}$ Prawa, przywileje i statuta miasta Krakowa 1507-1795 [Rechte, Privilegien und Statuten der Stadt Krakau 1507-1795], t. 1: 1507-1586, z. 1, red. F. Piekosiński Kraków 1890, nr 17; J. Bieniarzówna, J.M. Małecki, op. cit., S. 55.

${ }_{22}$ Prawa, przywileje i statuta miasta..., t. 1, nr 24; J. Ptaśnik, Miasta i mieszczaństwo..., S. 97-99; idem, Walki o demokratyzacje Lwowa od XVI do XVIII wieku [Der Kampf um die Demokratisierung der Stadt Lemberg im 17.-18. Jh.], „Kwartalnik Historyczny” 1925, t. 39, S. 234 235; idem, Dokumenty objaśniające Quadragintavirat w Krakowie i Lwowie [Das Quadragintavirat in Krakau und in Lemberg erläuternde Urkunden], „Kwartalnik Historyczny” 1925, t. 39, S. 315317; M. Bogucka, H. Samsonowicz, op. cit., S. 463. 
völlig an Einfluss ${ }^{23}$. Weil es dann auch nicht gelang, den Grundsatz durchzusetzen, dass die Nominierung für die Gerichtsbank (die in der Regel den Weg in den Rat öffnete) nur von den Mitgliedern des Quadragintavirats vorgenommen werden konnte, wollten sich die Mitglieder - wohl aus Furcht um die eigenen Pfründe nicht mit dem Rat anlegen, womit die Institution der 40 Männer zu einem dem Rat untergeordneten Organ wurde und seine Funktion als Vertretung aller Bürger einbüßte, so wie einst der Stadtrat.

An dessen Stelle trat eine weitere, breiter gefasste Vertretung des Volks: die Versammlung der Schöffen, Kaufleute und Zunftmeister (communitas). Diese Körperschaft erwuchs aus einer geheimen Verschwörung der Krakauer Einwohner, die mit der Besetzung der Stadt in den Jahren der schwedischen „Einfälle“ im Jahre 1657 im Zusammenhang stand ${ }^{24} .1668$ verlieh König Jan Kazimierz dieser Bruderschaft aus Bürgern dann weitreichende Privilegien, wodurch diese faktisch die bisherigen Rechte des Quadragintavirats übernahmen. Die Communitas war eine Versammlung dreier Stände: der Schöffen, der Kaufleute und der Handwerker, wobei jeder eine Stimme hatte. Die Prozedur und der Verlauf der Beratungen war (wie übrigens in jeder Körperschaft) sehr zeitraubend. Die Versammlungen des Volkes fanden auf Initiative des Rates statt, die Stimme ergriffen allerdings nur der Bürgermeister im Namen des Rates und der Älteste der Schöffen im Namen der Volksvertreter. Der Bürgermeister stellte die Fragen vor, zu denen die communitas Stellung beziehen sollte, danach hielten die Volksvertreter Rat und gaben unter Vermittlung des Ältesten der Schöffen ihr Urteil ab ${ }^{25}$. Diese Institution, die sich bis Ende des 18. Jh. hielt, ist ein interessantes Beispiel für bürgerliche Aktivitäten. Von entscheidender Bedeutung waren hier die Kompetenzen der Volksvertreter im Bereich Finanzen, denn der Rat konnte ohne deren Zustimmung keine Steuern beschließen oder keine städtischen Gelder ausgeben, die über 100 Zloty lagen - daher bildeten derlei Fragen zumeist den Hauptgegenstand der Beratungen. Der Rat wurde zwar regelmäßig zur Abrechnung der eingenommenen Steuern befragt, allerdings war die Aufsicht über die Finanzen nicht allein auf die Anhörung von Finanzberichten beschränkt. Die Vertreter des Volks hatten stets Einsicht in die öffentlichen Finanzen, wobei sie an der Erhebung der Gelder in jeder Phase beteiligt waren. Die städtischen Behörden informierten die Vertreter des Volks über die wichtigsten Ereignisse in der Stadt oder berieten mit ihnen die Vorbereitungen zu Feierlichkeiten oder Fronleichnamsprozessionen, zu Fragen

${ }^{23}$ J. Ptaśnik, Walki o demokratyzację Krakowa w wieku XVII-XVIII [Der Kampf um die Demokratisierung der Stadt Krakau in 17.-18. Jh.], „Kwartalnik Historyczny” 1929, t. 44, S. 2-5; J. Bieniarzówna, Mieszczaństwo krakowskie..., S. 103-126.

${ }^{24}$ Jagiellonen-Bibliothek in Krakau, Sign. 5350, S. 358; J. Bieniarzówna, J.M. Małecki, op. cit., S. 382.

${ }_{25}$ S. Krzyżanowski, O sejmikowaniu mieszczaństwa krakowskiego [Über den Parlamentarismus der Krakauer Stadtbürger], „Rocznik Krakowski” 1899, t. 2, S. 207-224. 
des Brandschutzes oder über die Ordnung auf den Straßen und in den Parzellen. Wenn wir jetzt noch den umfangreichen Anteil der Bürger an der Beilegung von Grenzfragen, der Steuererhebung und Zunftgerichten berücksichtigen, wird die Skala des bürgerlichen Engagements im Leben der autonomen städtischen Gemeinde durchaus klar.

Zusammenfassend kann man betonen, dass die im Mittelalter gestaltete und innerhalb von nächsten Generationen nach der Lokation etwas modifizierte Gesellschaftsordnung der Stadt mit ihren Hauptinstitutionen: dem Rat, der Schöffenbank, der Vogtei und dem Quadragintavirat - fast bis zum Ende der Ersten Republik Polens überdauerte. Die Verfassung von 3. Mai 1791 führte dann eine neue Stadtordnung ein.

\section{LITERATURVERZEICHNIS}

\section{Quellen}

Jagiellonen Bibliothek in Krakau, Sign. 5350.

Prawa, przywileje i statuta miasta Krakowa 1507-1795 [Rechte, Privilegien und Statuten der Stadt Krakau 1507-1795], t. 1: 1507-1586, z. 1, red. F. Piekosiński Kraków 1890.

\section{Literatur}

Bieniarzówna J., Krakowska rada miejska w czasach saskich [Der Krakauer Stadtrat in der Zeit der Wettiner], „Rocznik Krakowski” 1976, t. 47.

Bieniarzówna J., Mieszczaństwo krakowskie XVII w. Z badań nad struktura społeczna miasta [Die Krakauer Bürgerschaft des 17. Jhs. Zur Forschungen der soziale Struktur der Stadt], Kraków 1968.

Bieniarzówna J., Malecki J.M., Dzieje Krakowa [Geschichte der Stadt Krakau], t 2: XVI-XVIII w., Kraków 1984.

Bogucka M., Samsonowicz H., Dzieje miast i mieszczaństwa w Polsce przedrozbiorowej [Die Geschichte der Städten und Stadtbürger in Polen vor den Teilungen], Wrocław 1986.

Bukowski W., Salomonowie herbu Łabędź. Ze studiów nad patrycjatem krakowskim wieków średnich [Die Familie Salomon mit Wappen Łabędź. Zur Studien über dem Krakauer Patriziat im Mittelalter], [in:] Cracovia. Polonia. Europa. Studia z dziejów średniowiecza ofiarowane Jerzemu Wyrozumskiemu w sześćdziesiąta piąta rocznice urodzin i czterdziestolecie pracy naukowej [Festschrift für Jerzy Wyrozumski], Kraków 1995.

Bukowski W., Noga Z., Ustrój miasta Krakowa w XIII-XVIII wieku [Die Grundordnung der Stadt Krakau in 13.-8. Jh.], [in:] Kraków europejskie miasto prawa magdeburskiego 1257-1791 [Krakau europäische Stadt des Magdeburger Rechts 1257-1791], Kraków 2007.

Krzyżanowski S., O sejmikowaniu mieszczaństwa krakowskiego [Über Parlamentarismus der Krakauer Stadtbürger], „Rocznik Krakowski” 1899, t. 2.

Niwiński M., Wójtostwo krakowskie w wiekach średnich [Das Krakauer Vogtamt im Mittelalter], Kraków 1938.

Noga Z., Krakowska rada miejska w XVI wieku. Studium o elicie władzy [Der Krakauer Rat im 16. Jh. Studium über die Herschaftselite], Kraków 2003.

Noga Z., Rola samorzadu w rozwoju miasta w XIII-XVIII wieku [Die Rolle der Selbsverwaltung in der Entwicklung der Stadt], [in:] Kraków. Nowe studia nad rozwojem miasta [Krakau. Neue Studien über die Stadtentwicklung], red. J. Wyrozumski, Kraków 2007. 
Noga Z., Urzędnicy miejscy Krakowa [Die Beamte der Stadt Krakau], cz. 2: 1500-1794, Kraków 2008.

Ptaśnik J., Dokumenty objaśniające Quadragintavirat w Krakowie i Lwowie [Die Urkunden erläuternd Quadragintavirat, in Krakau und in Lemberg], „Kwartalnik Historyczny” 1925, t. 39.

Ptaśnik J, Kilka słów o dawnej radzie [Ein paar Worte über den ehemaligen Rat], [in:] Obrazki z przeszłości Krakowa [Bilder aus der Vergangenheit Krakaus], Kraków 1902.

Ptaśnik J., Miasta i mieszczaństwo w dawnej Polsce [Die Städte und Stadtbürger in der alten Polen], Kraków 1949.

Ptaśnik J., Studia nad patrycjatem krakowskim wieków średnich [Studien über dem Krakauer Patriziat des Mittelalters], „Rocznik Krakowski” 1912, t. 15.

Ptaśnik J., Walki o demokratyzację Krakowa w wieku XVII-XVIII [Kampf um die Demokratisierung der Stadt Krakau in 17.-18. Jh.], „Kwartalnik Historyczny” 1929, t. 44.

Ptaśnik J., Walki o demokratyzację Lwowa od XVI do XVIII wieku [Kampf um die Demokratisierung der Stadt Lemberg in 17.-18. Jh.], „Kwartalnik Historyczny” 1925, t. 39.

Rajman J., Kraków. Zespót osadniczy, proces lokacji, mieszczanie do roku 1333 [Krakau. Siedlungskomplex, Lokationsprozess, Stadtbürger bis 1333], Kraków 2004.

Starzyński M., Krakowska rada miejska w średniowieczu [Der Krakauer Stadtrat im Mittelalter], Kraków 2010.

Wyrozumski J., Dzieje Krakowa [Geschichte der Stadt Krakau], t. 1: Kraków do schyłku wieków średnich [Krakau bis Ende des Mittelalters], Kraków 1992.

Wyrozumski J., Lokacja czy lokacje Krakowa na prawie niemieckim? [Die Lokation oder die Lokationen Krakaus nach dem deutschen Recht?], [in:] Kraków. Nowe studia nad rozwojem miasta [Krakau. Neue Studien über die Stadtentwicklung], red. J. Wyrozumski, Kraków 2007.

\section{SUMMARY}

The city of Cracow functioned from the times of its founding (1257) to the Constitution of 3 May 1791 on the Magdeburg Law, but the municipality also had local characteristics. In the beginning of the city's founding, the main role was played by hereditary mayors (wójt) and courtroom juries. After Władysław the Short had confiscated the mayor's office in 1312, as a result of a rebellion of Mayor Albert, the degradation of this body followed. From that time, the mayors performed only judicial and police function and they were dependent on city council.

This body was created shortly after the city had been founded. Initially appointed by the mayor and then by co-optation, it was the real representative of citizens. As a consequence of the rebellion of Mayor Albert, the municipality lost its entire autonomy; thereafter, the council was annually appointed by the monarch or his official, from the $15^{\text {th }}$ century - by the governor (wojewoda) of Cracow, who selected 8 councillors-in-office ( $r a j c a$ ) while the councillors, who had been in office previously, but were not selected in that given year, formed a 16-person old council. It was a lifelong office. Only towards the end of the $17^{\text {th }}$ century the council retrieved the right to choose new councillors. The body gained a privileged position in the city, accumulating in its hands all the most important competences, including nominations for aldermen and professional officials, with a scribe and liquidator at its forefront, but also the representation of the city in external affairs. Staffed with a small group of families, it became an oligarchic institution, advocating mainly the interests of its own group to the disadvantage of the entire population who, after all the conflicts, received in the $16^{\text {th }}$ century a right to control public finances and their own representatives who became referred to as a quadragintavirate. Finally, in the second half of the $17^{\text {th }}$ century a broader representation of common people was formed-communitas - which took over the function of the 
quadragintavirate. These structural institutions have upheld the autonomy of the municipality and for centuries have shaped civic attitudes of the inhabitants of Cracow.

Keywords: Cracow; cities' government; Magdeburg Law; city council; quadragintavirate

\section{STRESZCZENIE}

Miasto Kraków funkcjonowało od czasu lokacji (1257) do Konstytucji 3 Maja (1791) na prawie magdeburskim, ale ustrój gminy miejskiej miał także cechy lokalne. W początkach miasta lokacyjnego główną rolę odgrywali wójtowie dziedziczni i ława sądowa. Po konfiskacie wójtostwa przez księcia Władysława Łokietka w 1312 r., będącej skutkiem buntu wójta Alberta, nastąpiła degradacja tego organu. Odtąd wójtowie pełnili tylko funkcje sądowe i policyjne i byli zależni od rady miejskiej.

Ten organ powstał wkrótce po lokacji miasta. Początkowo mianowany przez wójta, a następnie przez kooptację, był rzeczywistym reprezentantem obywateli. Konsekwencją buntu wójta Alberta była utrata pełnej autonomii gminy miejskiej. Odtąd radę mianował corocznie władca lub jego urzędnik; od XV w. wojewoda krakowski wybierał 8 rajców urzędujących, a rajcy wcześniej urzędujący, nie wybrani w tym roku, tworzyli 16-osobową radę starą. Urząd był dożywotni. Dopiero w końcu XVII w. rada odzyskała prawo do wyboru nowych rajców. Organ ten zyskał uprzywilejowaną pozycję w mieście, skupiając w swoich rękach wszystkie najważniejsze kompetencje, w tym nominacje ławników i urzędników zawodowych, z pisarzem i syndykiem na czele, a także reprezentację miasta $\mathrm{w}$ kontaktach zewnętrznych. Obsadzany przez nieliczną grupę rodzin, stał się instytucją oligarchiczną, zabiegającą głównie o interesy własnej grupy na niekorzyść ogółu obywateli, którzy po konfliktach uzyskali w XVI w. prawo do kontroli finansów publicznych przez własną reprezentację, zwaną quadragintaviratem. Wreszcie w drugiej połowie XVII w. wykształciła się szersza reprezentacja pospólstwa (communitas), która przejęła funkcje quadragintaviratu. Te instytucje ustrojowe stały na straży autonomii gminy miejskiej i kształtowały przez wieki postawy obywatelskie krakowian.

Słowa kluczowe: Kraków; ustrój miast; prawo magdeburskie; rada miejska; quadragintavirat 